\title{
Research on Reform and Innovation for Application-oriented Advanced Mathematics Teaching
}

\author{
Zeyan Wang, Jing Yang, Xiao Han \\ Department of General Education \\ Army Engineering University of PLA \\ Nanjing, Jiangsu, China
}

\begin{abstract}
The existing common problems in current Advanced Mathematics teaching were found through a questionnaire. In order to deal with these problems, the study is aimed to provide five teaching forms based on the reform idea of application-oriented teaching of mathematics. Firstly, this work analyzed the importance of the consolidation of students' senior high mathematics foundation, secondly, discussed the necessity of strengthening mathematical concepts, thirdly explored supplementing mathematical application examples, fourthly elaborated adding mathematical experiment content in the process of teaching, and finally, it put forward the adoption of diversified methods for examination and the "club+" platform for practical application. According to the results, it is proved that this teaching reform can improve not only the teaching quality of Advanced Mathematics in engineering colleges but also students' innovative and practical abilities.
\end{abstract}

Keywords-Advanced Mathematics; Application-oriented; Mathematical Concepts; Mathematical Experiments; “Club +" Practice Platform

\section{INTRODUCTION}

As a compulsory public basic course for all majors in engineering colleges, Advanced Mathematicsmainly covers the limit and continuity of unary function, calculus of unary function, calculus of multivariate function, vector algebra and analytic geometry of space, infinite series and ordinary differential equation, with the characteristics of multiple content, long hour, high credit and relative abstract. Moreover, the study of Advanced Mathematics can not only lay a solid foundation for undergraduates to learn follow-up courses, but also a great exercise to improve their abstract thinking, logical reasoning, and independent learning. However, there exists an inevitable difficulty for the students to grasp Advanced Mathematics. As a result, many beneficial attempts have been made on the teaching reform of Advanced Mathematics [1-3] to improve the learning effect of Advanced Mathematics, including the mixed teaching based on MOOC and SPOC platforms [4].

To accurately grasp the learning status of Advanced Mathematics courses, a questionnaire survey was organized for some freshmen in the fall semester of 2016. Statistical analysis shows the following prominent problems:
(1) A variety of sources of students whose mathematical foundations are uneven. Based on the survey, six percent of the students surveyed learned only three kinds of trigonometric functions (sines, cosines, and tangent functions) in their high schools, while eleven percent of the students did not know about anti-trigonometric functions at all or only learned two kinds of anti-trigonometric functions (arcsine and arccosine functions). This aggravates students' difficulty in learning Advanced Mathematics because such knowledge is in frequent use in Advanced Mathematics.

(2) Same national programmed textbooks (such as Advanced Mathematics by Tongji University) used by most engineering colleges for the teaching of Advanced Mathematics. Students of different majors use the same textbook and are taught with the same content. As a consequence, students are overwhelmed by mathematical definitions, theorems, formulas, properties, examples, etc., which are not closely bound up with students' majors and practical applications. Moreover, the meaning of learning mathematics has been doubted by students, resulting in insufficient motivation and low interest in learning. According to the survey, nearly one-third of the students don't read textbooks carefully after class, and some students consider that textbooks are tedious and dominated by theories with few practical applications.

(3) Mathematics teachers' little understanding of the majors of students. It is the fact that most mathematics teachers are basically graduated from mathematics-related majors with a solid theoretical knowledge of mathematics, while they don't know much about students' majors, which makes them prone to attaching importance to the knowledge system of mathematics in teaching, instead of organic connection with the application of students' majors. As a result, four percent of the students surveyed expect more examples or application cases can be added in class, and some students propose a supplement of the history of mathematics or story of mathematicians.

\section{ApPliCATION-ORIENTED AdVANCED MATHEMATICS TEACHING REFORM}

To address the foregoing common problems, it is necessary to make full use of the basic, applied and instrumental features of Advanced Mathematics courses, effectively consolidate 
mathematical foundation, strengthen mathematical concepts, supplement application content, reform examination methods, and build practice platforms for the improvement of students' capabilities to analyze and solve problems by mathematics.

\section{A. Consolidating mathematical foundation}

In view of the weak foundation in senior high mathematics of some students, the "advanced course for college mathematics" has been launched and the Textbook of Advanced Course for College Mathematics has been prepared accordingly to make up for the basic content of Advanced Mathematics, mainly including trigonometric functions, inverse trigonometric functions, parametric equations, polar coordinate systems, spherical coordinate systems and orthogonal curvilinear coordinate systems, arrangements and combinations.

A questionnaire survey and a placement test shall be carried out before class. Depending on the survey and test results, teachers should reasonably choose teaching content for extra tutoring of 2-3 classes to make up for the students' break of knowledge.

\section{B. Strengthening mathematical concepts}

In the long process of Advanced Mathematics teaching, there exists a common problem in students, namely, inaccurate and poor understanding of mathematical concepts, which may affect the learning of this course and subsequent courses, and even students' confidence in learning. Mathematical concepts are viewed to be fundamental and critical in Advanced Mathematics. They are the logical starting point of Advanced Mathematics, the most basic unit of theorems, formulas and methods, and the core for students to learn mathematical knowledge and grasp mathematical thinking. Therefore, concept teaching plays an important role in learning Advanced Mathematics.

There are more than 360 main concepts in Advanced Mathematics. To help students clarify the relationship between concepts, a diagram of concept connections has been created to present the logical relationship between concepts, and visualize their first time of appearance, background, and the mathematicians who contributed to them. Besides, an auxiliary textbook titled Teaching and Learning of Advanced Mathematics Concepts has been compiled, describing the background of concepts generation, four ways of expression of concepts (text, graph, list, and formula), concepts understanding and discrimination, counter-examples, applications and training questions. It is recommended that the teaching of concepts shall focus on question orientation and historical evolution to make teaching natural, interesting, and vivid, thus leading to easy understanding and cognition of concepts.

\section{Supplementing practical contents}

Students in engineering colleges study mathematics for practical application purpose. In the practice of teaching, therefore, we adhere to the principles of combining mathematics with student majors, practical application, and information technology, and we have added the following two aspects.
The first is to add more mathematical examples. Some examples are extracted from the courses that students may learn, such as "college physics", "fundamentals of electronic circuits", "principles of communication”, “computer network”, "principles of mechanics", etc., which do not introduce background in detail, but directly list mathematical expressions, making students realize the importance of advanced mathematical knowledge. Some examples are created based on teachers' subjects. For instance, when teaching the maximum value theorem, a question has been designed on "how to solve the optimal path problem in compliance with certain constraint conditions in communication link", arousing the great interest of students in communication major. Besides, some examples are closely associated with real life, such as the introduction of bank deposit interest in the teaching of the second important limit and the raising of question on "why cubic curve should be adopted in railway turning design" in the teaching of curvature, which can stimulate students' interest in learning.

The second is to add more mathematical experiments. To mitigate students' fear of Advanced Mathematics calculation, it is proper to add mathematics software and experiments in teaching. In the form of an experiment project, MATLAB software is used for solving problems. In addition to some simple mathematical application experiments such as Fourier transform and its application as well as least square method, 20 experiment projects closely related to textbook content have been designed, including condition of function of one variable; graphs of space curve and curved surface; definite integral and its application; multiple integral and its application; series summation and differential equation solving. The content of mathematical experiments is conducive to training students' preliminary programming ability and basic mathematical modeling ability.

\section{Innovative assessment methods}

To motivate students to focus on the learning process, the assessment of Advanced Mathematics courses is reformed to replace the method of determining academic result just by final examination with diversified methods of assessment. That is, the course assessment consists of two parts, i.e., formative assessment (40\%) and summative assessment (60\%).

Formative assessment result $=$ classroom performance + regular assignment + stage test score

Class performance has a total of 5 points. The students who discuss or answer questions correctly in class can win 1 or 2 points, and at the end of the semester, the class performance scores of each student are counted to calculate the average score of the whole class students. The class performance above or equal to the average score is recorded as 5 points, and the class performance below the average score is recorded as 1 point. Based on this, it can force students to listen to lectures in class carefully. The regular assignment also has a total of 5 points. Teachers have to correct and grade each assignment (five-point system), and at the end of the semester, the average score of the five assignments with top five low scores is calculated as the student's score of regular assignment, which can make students take each assignment seriously. The phase test includes a chapter test and mid-term test, both of which are the closed-book exam, with each accounting for 15 points. In 
order to enable students to know their score and position in class, and further to adjust their efforts pertinently, the stage test result must be announced in class.

The summative assessment is the final examination of the course, which is a closed-book exam with questions made by the third party with the regulation that any student who doesn't pass the final examination will be deemed to fail the course. As a result, this scoring method may force students to pay more attention to their daily learning process.

\section{E. Building a "club +" practical education platform}

Li Daqian, an academician, once pointed out that "we should try to combine mathematics with practical background and realistic prototype, and not turn mathematics into metaphysics", and "the disconnection between mathematics and the outside world means the disconnection between mathematics and real life. Simply from concept to concept and from formula to formula, mathematics will become the water without sources and the trees without roots, inevitably making math teaching dull and boring. As a result, it is impossible to impart knowledge comprehensively and profoundly, give students the inspiration of mathematical thought and spiritual essence, and truly meet the requirements of mathematics teaching.” [5]

To develop students' ability to solve practical problems by Advanced Mathematics knowledge, in addition to the practice such as "mathematics experiments" and "mathematical modeling", great effects have been made to make full use of the "second classroom", and set up math competition and modeling clubs to select those with high teaching level, strong affinity and rich practical experience as instructors. Moreover, stable activity places and adequate financial support have been provided with the built of "club +" practical education platform to help students digest course knowledge and exercise their abilities of math practical application and innovative practice, which consists of "club + practical course", "club + project research", "club + skill training”, "club + academic exchange”, "club + brand activity" and "club + discipline competition" etc.

In the club, practical courses such as "mathematical software and application" and "mathematical modeling method" are launched to help students get familiar with MATLAB, LINGO and other software, and master mathematical experiments and basic modeling methods. Teachers are organized and guided to select and publish a certain number of small subjects from the mathematical modeling test questions, scientific research topics and teaching expansion content over the years, and then the students are required to form their own teams, select topics and conduct independent research, which enables them to understand the basic processes and methods of scientific research, and apply the knowledge they have learned to solve practical problems. Classified skills training, such as scientific research methods, thesis writing, software programming, and modeling, is launched for students to choose based on their foundation and interests. Besides, regular academic exchange activities are carried out, including inviting experts to give lectures, conducting communication with other schools, other clubs and within the club, and organizing students to participate in or plan academic conferences, etc., so as to broaden students' horizon and cultivate their abilities of organization and coordination. In each November, the "Mathematics Carnival" is held, which includes interesting mathematics competition, expert forum, lecture of mathematics masters and mathematics development history, club summary and commendation meeting, new recruitment activity, etc., which is conducive to attracting students and teachers to participate in, and gradually forming the club activity brand. College Advanced Mathematics competitions and mathematical modeling competitions are also held, and for this purpose, seeded players are selected to participate in relevant national and provincial competitions. Moreover, competition platform at three levels, namely, university platform, provincial platform, and national platform, is built to attain the goals of promoting education, learning, and innovation through competition.

\section{PRACTICAL RESUltS AND ANALYSES}

Remarkable results have been achieved since the implementation of Advanced Mathematics reform. The questionnaire survey at the beginning of 2019 shows that, nearly $70 \%$ of the freshmen surveyed spent more than one hour (included) on mathematics learning every day; the number of students who can actively read textbooks or reference books after class nearly doubled; the failure rate of final examination decreased and the average score increased; teachers and management officials all felt that students focused more on mathematics study, with better study atmosphere, for example, more students carefully listened and took notes, completed homework and corrected wrong questions, and asked more questions.

Good results have also been gained in subject competitions. Since 2012, our students have participated in the finals of national mathematics competitions for college students, and won 6 first prizes, 3 second prizes and 7 third prizes, ranking among the top in our province; participated in mathematical modeling contests, and won 15 first prizes and 30 second prizes in the national mathematical modeling contest for college students; won 1 special prize nomination, 13 first prize and 30 second prize of American mathematical modeling contest for college students. Students have published more than 30 academic papers and gained 4 national utility model patents.

\section{CONCLUSION}

Considering the existing common problems in current Advanced Mathematics teaching in engineering colleges, the application-oriented mathematics teaching reform was implemented. Five measures are proposed to solve the problem, first consolidating students' senior high mathematics foundation, second strengthening mathematical concepts in teaching, third supplementing mathematical application examples, fourth adding mathematical experiment content, fifth adopting diversified methods of examination, and building a "club+" platform in practical application to strive for improvement of students' capabilities to analyze and solve problems by mathematics. The practice shows that this teaching reform can improve not only the teaching quality of Advanced Mathematics in engineering colleges but also students' innovative and practical abilities. 


\section{REFERENCES}

[1] J.C.Kuang, "Reflections of Reforming of Mathematics Education in Universities for 60 Years, ” Journal of Mathematics Education, vol. 19 , No.6, pp. 1-5, Dec.2010 (In Chinese)

[2] L. Li, "Research Progress of Advanced Mathematics Teaching Reform," Collage Mathematics, vol. 23, No.4, pp. 21-26, Aug.2007 (In Chinese)

[3] J.J. Wang, G. H. Xu, and S.K. Wang, "Practice and Review: The Teaching Method Reform for Advanced Mathematics, " Collage Mathematics, vol. 26, No.4, pp. 4-6, Aug.2010 (In Chinese)
[4] X. Fang, H.L.Chen, and Y.Q. Guo, "Research on Teaching Method Reform of Advanced Mathematics Course for Engineering Application," University Education, vol. 5, No.1, pp. 104-105, Jan.2016 (In Chinese)

[5] Z.Y. Wang, J. Yao, "Practice and Thinking of Hybrid Advanced Mathematics Teaching Mode Based on SPOC, ” College Mathematics, Vol.33, No.1, pp.91-95, Feb.2017 (In Chinese)

[6] D.Q. Li, "Discussion on the Objectives and Methods of College Mathematics Teaching,” China University Teaching, Vol.31, No.1, pp.7-10, Jan.2009 (In Chinese) 